\title{
Konservasi Lamun untuk Keberlanjutan Sumberdaya Ikan di Perairan Pesisir Indonesia
}

\author{
Abdul Syukur ${ }^{* 1}$ \\ ${ }^{1)}$ Program Studi Pendidikan Biologi PMIPA FKIP Universitas Mataram; Jalan Majapahit \\ No 56 Mataram Nusa Tenggra Barat; Phone: +62 370 623873; Fax: +62 370634918 \\ *) Corresponding author: Abdul Syukur - Email: syukur_unram@ymail.com,
}

\begin{abstract}
ABSTRAK
Lamun berperan penting dalam penyediaan habitat keragamn jenis ikan, khususnya yang masih dalam massa juvenil. Peper ini bertujuan untuk mendiskripsikan nilai konservasi lamun untuk keberlanjutan sumberdaya ikan di perairan pesisir Indonesia. Sumber data yang digunakan adalah data sekunder dari dokemen yang relevan. Analisis data dilakukan secara diskriptif. Data yang dianalisis adalah data tentang fungsi ekologi lamun untuk keberlanjutan suberdaya ikan dan data tentang status konservasi lamun di perairan pesisir Indonesia. Hasil analisis menunjukkan bahwa keberdaaan padang lamun dibutuhkan oleh keragaman jenis ikan, khususnya pada tahapan yang sangat krusial yaitu pada tahapan pembesaran, terutama dari jenis ikan demersal. Selain itu usaha konservasi lamun khususnya pada areal lamun di luar kawasan konservasi belum ada standar operasional untuk menekan tingkat eksploitasi yang sudah mengancam kelestarisn lamun. Kesimpulannya adalah dibutuhkan standar konservasi lamun di luar kawasan konservasi perairan yang telah ada saat ini sebagai strategi pengelolaan perikanan berkelanjutan berbasis ekologi di perairan pesisir Indonesia.
\end{abstract}

Kata kunci: Konservasi Lamun, Ikan dan Perairan Pesisir Indonesia.

\begin{abstract}
Seagrass has a vital role in providing habitat diversity of fish species, especially those who are in the juvenile mass. This article aims to describe the seagrass conservation value to the sustainability of fish resources in the coastal waters of Indonesia. Source data used are secondary data from relevant dokemen. The data were analyzed descriptively. The analyzed data is data about the ecological function of seagrass to the sustainability of fish resources and data on the conservation status of seagrass in the coastal waters of Indonesia. The analysis showed that the existence of seagrass required by the diversity of fish species, especially at crucial stages, namely the juvenile stages, especially of demersal fish species. In addition seagrass conservation efforts, especially in areas outside of protected areas seagrass yet operational standards to reduce the level of exploitation that have been threatening the survival of seagrass. The conclusion is required seagrass conservation standards outside the water conservation areas that already exist today as a sustainable fishery management strategies based on the ecology of coastal waters of Indonesia
\end{abstract}

Keywords: Seagrass Conservation, Fish and Coastal Water Indonesia. 


\section{PENDAHULUAN}

Konservasi adalah usaha untuk melestarikan tumbuhan, hewan dan komunitas alami yang mewakili keanekaragaman kehidupan di bumi dengan melindungi tanah dan air yang dibutuhkan untuk bertahan hidup (Bjork, et al., 2008). Visi tersebut mengintegrasikan aspek ekologi, sosiologi, antropologi, ilmu politik, ekonomi dan disiplin lain dalam perencanaan konservasi (Leenhardt et al., 2015). Dalam konsep biologi konservasi lamun tidak hanya ditujukan untuk memelihara dan mendukung kebutuhan manusia, tetapi keterkaitan yang kuat dengan kesehatan bioma, produktivitas muara dan keberlanjutan keanekaragaman hayati (Kenworthy et al., 2006). Oleh karena itu dibutuhkan kebijakan sebagai intrumen penting untuk mencapai tujuan konservasi (Kamal dan Khan, 2009).

Konservasi padang lamun sering dikaitkan dengan keberlanjutan ekonomi dan jasa ekologi (Sheppard et al., 1992; Costanza et al., 1997; . Orth et al., 2006.). Jasa ekologi lamun seperti keterkaitan antara kepadatan lamun dengan hewan mikroskopis dan tumbuhan (epifit) yang merupakan makanan utama bagi ikan (Hemminga dan Duarte, 2000) dan sebagai produsen utama, habitat hewan dan tumbuhan serta pendukung jaring makanan (Parrish 1989; Short et al., 2000). Selain itu areal lamun adalah habitat penting keragaman jenis ikan komersial, ikan yang bermigrasi, kelompok burung air, manatee, dugong, dan kura-kura laut, serta berperan dalam stabilisasi sedimen dan perlindungan pantai (Kenworty et al., 2006).
Selanjutnya lamun pada sistem ekologi di lingkungan laut berperan untuk mendukung komunitas ikan, terutama pada sebagian tahapan siklus hidup, sehingga sangat penting untuk keberlanjutan sumber daya perikanan pesisir (Beck et al., 2001;. Nagelkerken 2009), sumber makanan dan tempat mencari makan kura-kura dan ikan duyung (Abdulqader and Miller, 2012; Preen et al., 2012). , dan meningkatkan kualitas air (Duffy, 2006). Selain itu padang lamun memiliki peran dalam penyerapan karbon (Fourqurean et al., 2012; Alongi et al., 2015). Secara ekonomi, tempat pembibitan penting udang penaeid, tiram mutiara dan organisme lain untuk perikanan komersial (Erftemeijer and Shuail, 2012).

Indonesia sebagai negara kepulauan memiliki areal padang lamun yang cukup luas, dan diestimasi mencapai $30.000 \mathrm{~km}^{2}$ (Green and Short, 2003). Namun demikian status padang lamun sebagai ekosistem penting di perairan pesisir Indonesia kurang dikenal seperti ekosistem lain yaitu terumbu karang dan mangrove masih terpinggirkan dalam praktik pengelolaan (Nadiarti et al., 2012), meskipun telah teridentifikasi sumber kerusakan lamun yaitu pembangunan pelabuhan, konversi lahan dan pemanfaatan tidak ramah lingkungan (Tomascik et al., 1997; Dahuri 2003). Selanjutnya (UNEP 2008) menjelaskan jumlah kerusakan lamun di perairan pesisir Indonesian diperkirakan sebesar 30-40 \% sejak 1960s, dan beberapa penelitian telah melaporkan tentang kerusakan lamun di perairan pesisir Indonesia ( (Kiswara et al., 1994; Kiswara 1999; Syukur et al., 2012). 
Upaya konservasi lamun berkaitan dengan fungsi perlindungan dan pelestarian keragaman dan kekayaan spesies ikan (Horinouchi dan Sano, 1999; Elhaweet et al., 2011; AmboRappe et al., 2013). Selain itu untuk keberlanjutan produktivitas perikanan pesisir dan keamanan pangan (Unsworth dan Cullen 2010; Cullen-Unsworth dan Unsworth, 2013). Namun demikian fungsi esensial padang lamun untuk keberlanjutan sumberdaya ikan dan penyediaan stok ikan di perairan pesisir Indonesia belum mendapat perhatian sereus. Oleh karena itu artikel ini bertujuan untuk mendiskripsikan keragaman jenis ikan yang berasosiasi dengan lamun dan status konservasi lamun di perairan pesisir Indonesia.

\section{Bahan dan Metode}

Data dan informasi yang digunakan dalam artikel ini bersumber dari literatur (buku, jurnal, proseding dan peraturan perundangan) yang berkaitan dengan konservasi, asosiasi ikan dengan lamun, perlindungan padang lamun dan status konservasi lamun di perairan pesisir Indonesia. Data dan informasi dianalisis secara diskriptif yaitu melalui proses sintesis dan evaluasi untuk mendapatkan kesimpulan yang dapat merepresentasikan fungsi ekologi lamun terhadap keragaman jenis ikan dan status konservasi lamun di luar kawasan konservasi perairan di perairan pesisir Indonesia.

\section{Hasil dan Pembahasan}

\subsection{Asosiasi ikan dengan lamun}

Keragaman spesies ikan di padang lamun disebabkan karena areal padang lamun terdapat kelimpahan makanan, tempat pembesaran, dan nilai tutupan lamun dapat memberikan tempat untuk berembunyi dari predator (Anand dan Pilla, 2007). Kelompok ikan dalam menggunakan areal padang lamun dapat bersifat sementara dan permanen, terutama dari kelompok ikan komersial seperti Sillago sihama, Gerres erythrurus, Sillago aeolus, Sardinella Albella, Thryssa hamiltonii, Plotosus lineatus, Gerres oyena dan Atherinomorus duodecimalis (Phinrub et al., 2014). Dalam hal ini ikan yang berasosiasi dengan padang lamun dapat dikelompokkan dalam tiga katagori (Tabel 1). Selain itu kelompok ikan yang beraososiasi dengan padang lamun didominasi oleh jenis ikan dengan habitat lain (Syukur et al., 2012). Namun demikian jenis ikan seperti Siganus canaliculatus, Monacanthus chinensis, dan Terapon puta lebih sering ditemukan pada padang lamun (Sichum and Tantichodok, 2013). Studi lain memberikan bukti bahwa kompleksitas struktural habitat lamun terkait dengan kelimpahan dan biomassa ikan (AmboRappe et al., 2013). Selain komplesitas habiat dan faktor alam seperti pasang surut telah membuktikan adanya pergerakan ikan dari habitat lain yang meningkatkan keragaman jenis ikan pada padang lamun (Chen-Lu et al., 2014) dan pola pemanfaatan habiat lamun oleh keragaman jenis ikan dapat menjadi dasar dalam memperkirakan produksi ikan (Hammerschlag et al., 2009). 
Satu hasil penelitian melaporkan ditemukan 1.922 individu ikan pada padang lamun yang teridri dari 62 species dalam 35 famili dan jenis famili yang dominant adalah Leiognathidae 7 species (Leiognathus stercorarius, L. jonesi, $L$. decorus, L. splendens, $L$. equulus, Secutor insidiator dan Gazza minuta), Engraulidae 3 species (Thryssa hamiltonii, Stolephorus indicus dan Thryssa scratchleyi), Gerreidae 3 species filamentosus), Hemiramphidae 3 species (Hyporhamphus limbatus, Halichoeres bicolor dan Zenarchopterus buffonis), Platycephalidae 3 species (Grammoplites scaber, Platycephalus indicus and Cociella punctata) and Tetraodontidae 3 species (Lagocephalus spadiceus, Lagocephalus lunaris dan Chelonodon patoca), spesies yang dominan adalah Sillago sihama, Leiognathusjonesi dan Gerres erythrourus (Phinrub et al., 2014).

Tabel 1. Tiga kategori utama ikan hadir di padang lamun yaitu kategori pertama yang hadir terutama sebagai pada saat massa juvenil, ikan di kategori kedua yang hadir di semua tahapan siklus hidup dan ikan di kategori ketiga yang hadir terutama setelah dewasa

\begin{tabular}{|c|c|c|}
\hline $\begin{array}{l}\text { Hadir pada saat massa } \\
\text { juvenil }\end{array}$ & $\begin{array}{l}\text { Hadir pada semua siklus } \\
\text { hidup }\end{array}$ & Hanya pada saat dewasa \\
\hline Siganus sutor & Leptoscarus vaigiensis & Stethojulis strigiventer \\
\hline Lethrinus lentjan & Calotomus spinidens & Amblygobius albimaculata \\
\hline Lethrinus variegatus & Cheilio inermis & Pteragogus flagellifer \\
\hline Gerres oyena & Sphyraena flavicauda & Carangoides fulvoguttatus \\
\hline Lutjanus fulviflamma & Hemiramphus far & Diagramma pictum \\
\hline Parupeneus barberinus & Scolopsis ghanam & $\begin{array}{l}\text { Herklotichthys } \\
\text { quadrimaculatus }\end{array}$ \\
\hline Lethrinus mahsenoides & Fistularia commersoni & Tylosuruscrocodilus crocodilus \\
\hline Siganus stellatus & Lactoria cornuta & \\
\hline Scarus ghobban & Pelates quadrilineatus & \\
\hline Upeneus tragula & $\begin{array}{l}\text { Cheilodipterus } \\
\text { quinquelineatus }\end{array}$ & \\
\hline Plectorhinchus gaterinus & Chrysiptera annulata & \\
\hline Naso brevirostris & Cheilinus trilobatus & \\
\hline Lutjanus gibbus & Petroscirtes variablis & \\
\hline Plotosus lineatus & $\begin{array}{l}\text { Novaculichthys } \\
\text { macrolepidotus }\end{array}$ & \\
\hline $\begin{array}{l}\text { Parupeneus macronema } \\
\text { Hipposcarus harid } \\
\text { Lethrinus harak }\end{array}$ & & \\
\hline
\end{tabular}

Sumber: (Gell and Whittington, 2002)

Penelitian yang berkaitan dengan asosiasi ikan pada padang lamun di perairan pesisir Indinesia telah dilakukan pada beberapa lokasi padang lamun, diantaranya adalah di Teluk Banten
(Hutomo, 1985), perairan pantai Barat Sumatra (Ridho, 1999), perairan Teluk Awur Jepara (Merryanto, 2000), fungsi padang lamun (seagrass) sebagai area mencari makan ikan terumbu karang 
(Supratomo, 2000), Taman Nasional Laut Wakatobi (Bell et al., 2007; Unsworth et al., 2007), , Teluk Kotania dan Pelitajaya (Supriadi, 2009), padang lamun Pulau-Pulau Derawan Kalimatan Timur (Marasabessy, 2010)

\subsection{Perlindungan Habitat Lamun}

Lamun di wilayah pesisir mmendapat ancaman dari proses sedimen dan limpasan nutrien, gangguan fisik, invansi spesies, penyakit, praktek penangkapan ikan komersial, budidaya, secara berlebihan, ganggang, dan pemanasan global, telah menyebabkan degradasi lamun pada skala meter persegi hingga ratusan kilometer persegi (Orth et al., 2006). Oleh karena itu dibutuhkan inisiatif perencanaan sektor kelautan melalui koordinasikan dengan perencanaan yang bersifat komprehensif, seperti perencanaan daerah aliran sungai yang terintegrasi dengan perencanaan wilayah pesisir (Grech et al., 2012). Suatu akibat dari aliran nutrien yang tinggi ke wilayah pesisir adalah penurunan populasi ubur-ubur dan komunitas fauna lainnya sebagai akibat dari degradasi lamun akibat pengayaan nutrien (Stoner et al., 2014). Hasil tinjauan dari 45 studi kasus di seluruh dunia, bahwa total kerugian 21.023 ha vegetasi lamun rusak akibat akibat pengerukan (Erftemeijer and Lewis, 2006). Namun demikian degradasi lamun yang cukup luas telah menyebabkan meningkatnya kesadaran akan kebutuhan untuk perlindungan lamun, monitoring, manajemen dan pemulihan atau rehabilitasi.

Perlindungan habitat lamun tidak saja untuk kebutuhan keberlanjutan lamun, tetapi untuk keberlanjutan biodiversity. Disamping itu kontribusi ekonomi utama dari padang lamun untuk perikanan pesisir baik sebagai 'memancing' dan alasan 'penyediaan stoks pembibitan, sehingga perlunya menggabungkan lamun ke dalam kerangka kerja legislatif konservasi (Tuya et al., 2014). Oleh karena itu perlindungan habitat dalam dalam skema perlindungan laut sangat penting untuk melestarikan keanekaragaman hayati yang tinggi (Nordlund, 2006). Dalam hal ini perlindungan laut yang hanya berfokus untuk perlindungan terumbu karang harus diperluas ke areal padang lamun untuk keberlanjutan sumberdaya ikan (Verweij et al., 2008). Beberapa hasil penelitian berkaitan dengan pentingnya konservasi dan restorasi lamun yaitu studi mitigasi lamun untuk mempromosikan kepentingan masyarakat dalam kebijakan restorasi lamun ((Hotaling et al., 2011), studi tentang 
peran penting lamun sebagai areal penyediaan stok bibit dapat menjadi dasar yang lebih baik untuk membuat konservasi dan rehabilitasi habitat lamun ((Heck et al., 2003). Selain itu, lebih dari $20 \%$ dari spesies ikan komersial digunakan beberapa habitat, menyoroti pentingnya termasuk jenis habitat yang berbeda dalam daerah perlindungan laut untuk mencapai pengelolaan sumber daya yang efisien dan efektif (Honda et al., 2013). Studi lain menyebutkan bahwa upaya restorasi lamun dengan biaya $\$$ A10,000/ ha/tahun memiliki waktu pengembalian potensi kurang dari lima tahun, dan pemulihan biaya \$ A629,000 ha/tahun dapat meningkatkan jumlah ikan komersial (Blandon and zu Ermgassen, 2014). Oleh karena itu pengelolaan dan konservasi lamun adalah untuk mempertahankan peranan ekologi padang lamun untuk keberlanjutan sumberdaya hayati ikan (Gell and Whittington, 2002; Latuconsina et al ., 2012).

\subsection{Status Konservasi Lamun (Seagrass)} di Perairan Pesisir Indonesia

Konservasi pada dasarnya dilakukan untuk memelihara nilai-nilai esensial dari proses ekologi, melestarikan (preserving) keanekaragaman hayati, menjamin keberlanjutan penggunaan spesies dan ekosistem serta perlindungan budaya. Konservasi sumberdaya laut ditujukan untuk mengahasilkan: konservasi habiat dan keanekaraman hayati, (2) perlindungan terhadap eksploitasi, ancaman dan kelangkaan spesies serta populasi, mengembalikan kelangsungan hidup dari ekosistem, (4) pengelolaan perikanan, (5) kontrol laju eksploitasi, (6) melindungi tahap kritis dari sejarah hidup spesies dan (7) mengurangai dampak sekunder dari aktivitas perikanan (National Academy of Science USA, 2001; Clinton et al., 2004). Indonesia secara operasiobal untuk mencapai tujuan dan hasil konservasi laut dilakukan dalam bentuk konservasi perairan yaitu Taman Nasional Konservasi Laut, Konservasi Laut Daerah dan Konservasi Taman Wisata Laut (DKP 2008). Dalam hal ini status konservasi padang lamun secara faktual terintegrasi dalam tiap jenis kawasan konservasi.

Padang lamun sebagai sasaran konservasi, dari aspek ekologi telah memiliki kreteria yang cukup representatif sebagai sasaran konservasi untuk keberlanjutan sumberdaya ikan. Kreteria suatu areal menjadi areal konservasi yang reperesentatif adalah: (1) komprehensip yang dapat menggambarkan kemampuan suatu areal konservasi secara penuh untuk kelestarian 
keanekaragaman hayati, (2) kecukupan (adequacy) yang dapat menggambarkan tentang potensi areal konservasi dari keseluruhan areal geografisnya untuk keberlanjutan spesies dan komunitas ekologi dan (3) representatif yang menunjukkan kemampuan luas areal konservasi untuk menjamin kecukupan dari sejumlah individu dan spesies dapat hidup dalam jangka panjang (Jelbart et $a l ., 2008)$. Areal padang lamun sebagai areal konservasi dari aspek ekologi menunjukan cukup representatif untuk keberlanjutan sumberdaya ikan. Hal ini dapat dijelaskan dari beberapa hasil penelitian yang menjelaskan tentang peran padang lamun untuk keberlanjutan sumberdaya ikan di perairan pesisir Indonesia (Bell et al., 2007; Syukur et al,. 2012). Oleh karena itu perlindungan padang dalam bentuk konservasi dapat menjadi pilihan strategi untuk keberlanjutan sumberdaya ikan di perairan pesisir Indonesia.

\section{Kesimpulan}

Lamun yang tumbuh dan berkembang pada lingkungan perairan pesisir, keberadaanya memiliki makna yang sangat esensial untuk survive-nya keragaman spesies ikan. Nilai ekologi lamun yang cukup esensial bagi keragaman jenis ikan, ditandai oleh banyaknya spesies ikan yang memanfaatakan lamun pada massa juvenil, pada saat ikan sudah dewasa dan jenis ikan yang menggunkan habiat lamun pada semua siklus hidupnya seperti spesies ikan Leptoscarus vaigiensis, Fistularia commersoni, Cheilodipterus quinquelineatus, Lactoria cornuta, Calotomus spinidens, Cheilio inermis, dan Sphyraena flavicauda. Selanjutnya status konservasi lamun di perairan pesisir Indonseia saat ini masih bersifat partial yaitu terintegrasi pada kawasan konservasi perairan. Namun demikian pada areal lamun yang di luar kawasan konservasi belum ada strategi perlindungannya sebagai standar dalam usaha perlindungan lamun untuk keberlanjutan sumberdaya ikan.

\section{DAFTAR PUSTAKA}

Abdulqader E dan Miller J. 2012. Marine turtle mortalities in Bahrain territorial waters. Chelonian. Conservation and Biology, 11: 133138.

Alongi DM, Murdiyarso D, Fourqurean JW, Kauffman JB, Hutahaean A, Crooks S, Lovelock CE, Howard $\mathrm{J}$, Herr D, Fortes M, Pidgeon E dan Wagey T. 2015. Indonesia's blue carbon: a globally significant and vulnerable sink for seagrass and mangrove carbon. Wetlands Ecol Manage, DOI: 10.1007/s11273-015-9446-y 
Ambo-Rappe R, Nessa MN, Latuconsina $\mathrm{H}$ dan Lajus DL . 2013. Relationship between the tropical seagrass bed characteristics and the structure of the associated fish community. Open Journal of Ecology, 3 (.5); 331-342.

Anand PEV dan Pilla NGK 2007. Coral reef fish abundance and diversity of seagrass beds in Kavaratti atoll, Lakshadweep, India. Indian J. Fish. 54 (1) : 11-20.

Beck MW, Heck KL Jr, Able KW, Childers DL, Eggleston DB, Gillanders BM, Halpern B, Hays CG, Hoshino K, Minello TJ, Orth RJ, Sheridan PF, Weinstein MP. 2001. The identification, conservation, and management of estuarine and marine nurseries for fish and invertebrates. BioScience, 51:633-641.

Bell JJ, Unwort RKF, Wyle E, Smith DJ. 2007. Diel troflk of seagrass fish assemblages in the Wakatobi Marine National Park, Indonesia. Estuarine Coastal and Shelf Science. 81 -88.

Björk M, Short F, Mcleod E and Beer S. 2008. Managing Seagrasses for Resilience to Climate Change. IUCN, Pp 55.

Blandon A, zu-Ermgassen PSE. Quantitative estimate of commercial fish enhancement by seagrass habitat in southern Australia. Estuar Coast Shelf Sci. 2014; 141:1-8

Chen-Lu Lee, Yen-Hsun Huang, ChiaYun Chung and Hsing-Juh Lin. 2014. Tidal variation in fish assemblages and trophic structures in tropical Indo-Pacific seagrass beds. Zoological Studies, 53 (56): $1-13$.

Clinton J Dawes, Ronald C Phillips dan Gerold Morrison. 2004. Seagrass communities of the gulf coast of Florida: status and ecology. Florida Fish and Wildlife Conservation Commission Fish and Wildlife Research Institute and the Tampa Bay Estuary Program, pp 74.

Costanza, R., D'Arge R., De Groot R. 1997. The value of the world's ecosystem services and natural capital. Nature 387, 253-260.

Cullen-Unsworth L dan Unsworth R. 2013. Seagrass Meadows, Ecosystem services and Sustainability. Environment, 53 (3): $14-28$

Dahuri R. Keanekaragaman hayati laut: aset pembangunan berkelanjutan Indonesia, Jakarta, 2003, 38-52.

Departemen Kelautan dan Perikanan. 2008. Konservasi Surnberdaya Ikan Di Indonesia. Derektorat Jenderal Kelautan Pesisir dan Pulau-Pulau Kecil, Derektorat Konservasi dan Taman Nasional Laut kerjasama dengan Jepan International Cooperation Agency, 1 - 40.

Duffy JE. 2006. Biodiversity and the functioning of seagrass ecosystems. Mar Ecol Prog Ser , 311:233-250.

Erftemeijer P dan Shuail D. 2012. Seagrass habitats in the Arabian Gulf: distribution, tolerance thresholds and threats. Aquatic Ecosystem Health and Management. 15(S1): 73-83. 
Erftemeijer P L A and Lewis R R R. 2006. Environmental impacts of dredging on seagrasses: A review. Marine Pollution Bulletin, 52: 1553-1572

Elhaweet AE, Fishar MR, Geneid Y dan Abdel-Moula E. 2011. Assessment of fisheries and marine biodiversity of Sallum Gulf, Egypt. International Journal Of Environmental Science And Engineering, 1: 21-34.

Fourqurean JW, Duarte CM, Kennedy H, Marbà N, Holmer M, Mateo MA, Apostolaki ET, Kendrick GA, Krause-Jensen K, Glathery KJM dan Serrano O. 2012. Seagrass ecosystems as a globally significant carbon stock. Nature Geoscience, 5: 505-509.

Gell F R and Whittington M W. 2002. Diversity of fishes in seagrass beds in the Quirimba Archipelago, northern Mozambique. Mar. Freshwater Res., 2002, (53): 115121.

Grech A, Chartrand-Miller K, Erftemeijer $\mathrm{P}$, Fonseca M, McKenzie L, Rasheed M, Taylor $\mathrm{H}$ and Coles R. 2012. A comparison of threats, vulnerabilities and management approaches in global seagrass bioregions. Environmental Research Letters, 7:1-8.

Green EP, Short FT. 2003. World atlas of seagrasses. University of California Press, Berkeley

Hammerschlag N, Joseph E dan Serafy JE. 2009. . Nocturnal fish utilization of a subtropical mangrove-seagrass ecotone. Marine Ecology, 1-11
Heck Jr K L, Hays G and Orth R J. 2003. Critical evaluation of the nursery role hypothesis for seagrass meadows. Marine Ecology Progress Series, 253: 123-136.

Hemminga, M.A. and Duarte, C.M. (2000) Seagrass ecology. Cambridge University Press, Cambridge, 2000. Hutomo M dan Martosewejo S. 1977. The fishes of seagrass community on the west side of Burung Island (Pari Island, Seribu Islan) and their variation in abudance. Mar Res Indon, 17: 147172.

Honda K, Nakamura Y, Nakaoka M1, Wilfredo H. Uy, Fortes M D.2013. Habitat Use by Fishes in Coral Reefs, Seagrass Beds and Mangrove Habitats in the Philippines. PLOS ONE, 8 (8): 110.

Horinouchi, M. and Sano, M. 1999. Effect of changes in seagrass shoot density and leaf height on the abundanc and distribution patterns of juveniles of three gobiid fishes in a Zostera marina bed. Marine Ecology Progress Series, 183, 8794. doi:10.3354/meps 183087

Hotaling A S, Lingle R B, and Ankersen T T 2011. Comprehensive Seagrass Restoration Planning in Southwest Florida: Science, Law and Management. Sea Grant Law and Policy Journal, 4, (1): 61-78.

Hutomo M. 1985. Telaah Ekologik Komunitas Ikan Pada Padang Lamun (Seagrass, Anthophyta) di Perairan Teluk Banten. Disertasi. Pasca Sarjana IPB. Bogor. 
Jelbart J, Mohammad RS dan William G. 2008. The effectiveness of seahorses and Pipefish (Pisces : Syngnathidae) as a flagship group to evaluate the conservation value of estuarine seagrass beds. Aquatic Conservation Marine and Freshwater Ecosystems. (www Interscience Wiley), DOI : 10.1002/aqc. 1009.

Kamal AHM dan Khan MAA. 2009. Coastal and estuarine resources of Bangladesh: management and conservation issues. Maejo Int. J. Sci. Technol, 3(02), 313-342

Kenworthy WJ, Wyllie-Echeverria S, Coles RG, Pergent G, PergentMartini C. 2006. Seagrass Conservation Biology: An Interdisciplinary Science for Protection of the Seagrass Biome. In: Larkum AWD, Orth RJ, Duarte CM, editors. Seagrasses: Biology, Ecology and Conservation. The Netherlands:Springer. 595-623.

Kiswara, W. A review: Seagrass ecosystem studies in Indonesian waters In Wilkinson, CR, Sudara, S. and Chou, LM, Eds, Proceeding on the ASEAN-Australia Symposium on Living Coastal Resources, Chulalongkorn University, Bangkok, 1994: 259-282.

Kiswara W. Perkembangan Penelitian Ekosistem Padang Lamun Di Indonesia. Proseding Seminar Nasional Tentang Oseanolgy. Puslitbang Oseanology LIPI, Jakarta, 1999: 181 - 186.

Latuconsina H, Nessa M N dan Rappe R A. 2012. Komposisi Spesies Dan
Struktur Komunitas Ikan Padang Lamun Di Perairan Tanjung Tiram - Teluk Ambon Dalam. Jurnal Ilmu dan Teknologi Kelautan Tropis, 4 (1): 35-46.

Leenhardt P, Teneva L, Kininmonth S, Darling E, Cooley S dan Claude J. 2015. Challenges, insights and perspectives associated with using social-ecological science for marine conservation. Ocean \& Coastal Management, 115: 49-60.

Marasabessy MD. 2010. Sumberdaya Ikan di Daerah Padang Lamun Pulau-Pulau Derawan Kalimatan Timur. Oceanologi dan Limnologi di Indonesia. 36: 193-210.

Merryanto Y. 2000. Struktur Komunitas Ikan dan Asosiasinya dengan Lamun di Perairan Teluk Awur Jepara. Tesis. Pasca Sarjana IPB. Bogor.

Nadiarti NE, Djuwita I, Budiharsono S, Purbayanto A dan Asmus H. 2012. Challenging for Seagrass Management In Indonesia. Journal of Coastal Develpopment, 15 (3): 234-242.

National Academy of Science USA, 2001. Merine Protected Areas: Tools for Sustaining Ocean Ecosystem. National Academy Press Washington, DC, 17- 29.

Nagelkerken I.2009. Evaluation of nursery function of mangroves and seagrass beds for tropical decapods and reef fishes: and underlying mechanisms. In: Nagelkerken I (ed) Ecological Connectivity among Tropical Coastal Ecosystems. Springer, Netherlands, pp 357-399. 
Nordlund L. 2006. Human impact on invertebrate abundance, biomass and community structure in seagrass meadows - a case study at Inhaca Island, Mozambique. Report. Department of Animal Ecology, Uppsala University, Sweden Examensarbete biologi 20p.

Orth R J, Carruthers T J B, Dennison W $\mathrm{C}$, Duarte $\mathrm{C} \mathrm{M}$, Fourqurean $\mathrm{J} \mathrm{W}$, Heck Jr K L, Hughes A R, Kendrick G A, Kenworthy W J, Olyarnik S, Short F T, Waycott M, And Williams S L. 2006. A Global Crisis for Seagrass Ecosystems. BioScience, 56 (12): 987

Parrish JD. 1989. Fish communities of interacting shallow-water habitats in tropical oceanic regions. Mar Ecol Prog Ser, 58:143-160.

Phinrub W, Montien-Art B, Promya J and Suvarnaraksha A. 2014. Fish diversity and fish community in seagrass beds at Ban Pak Klong, Trang Province, Thailand. International Journal of Fisheries and Aquatic Studies, 2(2): 197-201

Preen A, Das H, Al-Rumaidh M. dan Hodgson A. 2012. Dugongs in Arabia; In: E. Himes, J. Reynolds III, L. Aragones, A. MignucciGiannoni, M. Marmontel (Eds.) Sirenian conservation: Issues and strategies in developing countries, University Press of Florida, Gainesville.

Short, F.T., D.M. Burdick, C.A. Short, R.C. Davis, and P.A. Morgan. 2000. Developing success criteria for restored eelgrass, salt marsh and mud flat habitats. Ecological Engineering, 15:239-252.
Ridho M R. 1999. Distribusi Biomassa dan Struktur Komunitas Sumberdaya Ikan Demersal di Perairan Pantai Barat Sumatra. Tesis. Pasca Sarjana IPB. Bogor

Sheppard C, Price A dan Roberts C. 1992. Marine ecology of the Arabian region: patterns and processes in extreme tropical environments. Academic Press, London

Sichum S and Tantichodok P. 2013. Diversity And Assemblage Patterns Of Juvenile And Small Sized Fishes In The Nearshore Habitats Of The Gulf Of Thailand. The Raffles Bulletin Of Zoology, 61(2): 795-809

Stoner E W, Yeager L A, Sweatman J L, Sebilian, S S and Layman C A. 2014. Modification of a seagrass community by benthic jellyfish blooms and nutrient enrichment. Journal of Experimental Marine Biology and Ecology, 461: 185192

Supratomo R T. 2000. Fungsi Padang Lamun (seagrass) sebagai Area Mencari Makan dengan Indikator Migrasi Ikan Terumbu Karang. Tesis. Pasca Sarjana IPB. Bogor.

Supriadi I H. 2009. Pemetaan lamun dan biota asosiasi untuk identifikasi daerah perlindungan lamun di Teluk Kotania dan Pelitajaya. Oceanologi dan Limnologi di Indonesia 35: 167- 183.

Syukur A, Wardiatno Y, Ismudi Mucbsin dan Kamal M M. 2012. Keanekaragaman jenis ikan pada padang lamun di perairan Tanjung 
Luar Lombok Timur. Jurnal Biologi Tropis, 13 (1): 1-7.

Syukur A, Wardiatno Y, Muchsin I dan Kamal M.M. Desain konservasi lamun untuk keberlanjutan sumberdaya ikan di Tanjung Luar Lombok Timur. Disertasi Pascasarjana Institut Pertanian Bogor Indonesia, 2012: 1-133

Tomascik T, Mah AJ, Nontji A and Moosa MK. Edn 2, The ecology of the Indonesien seas, Singapore, 1997, 829-906.

Tuya F, Haroun R and Espino F. 2014. Economic assessment of ecosystem services: Monetary value of seagrass meadows for coastal fisheries. Ocean \& Coastal Management, 96: 181-187.
UNEP.2008. National reports on seagrass in the South China Sea. UNEP/GEF/SCS Technical Publication No. 12.

Unsworth RKF, Bell JJ dan David J. Smith DJ. . 2007. Tidal fish connectivity of reef and sea grass habitats in the Indo-Pacific. Mar. Biol. Ass, 87: 1287-1296

Unsworth RKF, Cullen LC. 2010. Recognising the necessity for Indo Pacific seagrass conservation. Conserv Lett, 3:63-73.

Verweij M C, Nagelkerken I, Hans I, and Ruseler S M. 2008. Seagrass nurseries contribute to coral reef fish populations. Limnology Oceanography, 53(4): 1540-1547. 